\title{
Airport Environment and Passengers' Satisfaction with Safety
}

\section{Vania Ceccato \& Stefano Masci}

To cite this article: Vania Ceccato \& Stefano Masci (2017) Airport Environment and Passengers' Satisfaction with Safety, Journal of Applied Security Research, 12:3, 356-373, DOI: 10.1080/19361610.2017.1315696

To link to this article: http://dx.doi.org/10.1080/19361610.2017.1315696

曲 Published online: 20 Jul 2017.

Submit your article to this journal

Џlll Article views: 1

Q View related articles

View Crossmark data \lceil 


\title{
Airport Environment and Passengers' Satisfaction with Safety
}

\author{
Vania Ceccato ${ }^{a}$ and Stefano Masci ${ }^{b}$ \\ ${ }^{a}$ Department of Urban Planning and Environment, KTH Royal Institute of Technology, Stockholm, \\ Sweden; ${ }^{b}$ Department of Civil, Chemical, Environmental, and Materials Engineering, University of \\ Bologna, Bologna, Italy
}

\begin{abstract}
The objective of this article is to report patterns of passenger's satisfaction with their safety at an international European airport.' The study is based on an analysis of a 2014-2015 passenger safety survey with particular focus on the impact of the airport's environment on passenger safety. Chi-square analysis and binary logistic regression underpin the methodology used in the study. Findings show that about one third of passengers are dissatisfied with their perceived safety. Airport entrances, security checkpoints, boarding areas, toilets, and restaurants are places where passengers declare feeling less satisfied with their safety. Regardless whether passengers are arriving or departing, their satisfaction with safety is affected by their perception of an airport's environment (e.g., elevators, overall maintenance) and also by the overall experience of being in transit. Findings call for research and interventions that consider passenger safety as a multifaceted phenomenon and that adopt a whole-journey approach to transit safety.
\end{abstract}

\section{KEYWORDS}

Transit safety; transportation; binary logistic regression

\section{Introduction}

Perceived safety in transit environments is a complex phenomenon. First, how an individual declares his/her personal safety depends on the types of environments the individual is exposed to along the trip, some of these places are risky, while others are not. Second, even if an individual feels uneasy about a place, this does not necessarily mean that the environment is actually risky (the common mismatch between fear of crime and victimization risk). An individual's perceived safety at a particular time and place may reflect the perceived safety far beyond that point, perhaps along the trip and even before it started. Research has long shown that passenger's poor declared safety can be associated with individual factors, such as age, gender, but also fear of flying, the overall anxiety for the trip or the image of the airports as a target for terrorism (e.g., Dale \& Brian, 2007; Howard, Murphy, \& Clarke, 1983; Molotch,

CONTACTV Vania Ceccato $\otimes$ vania.ceccato@abe.kth.se $\Theta$ Department of Urban Planning and Environment, KTH Royal Institute of Technology, Drottning Kristinas väg 30, Stockholm, 10044 Stockholm, Sweden.

Color versions of one or more of the figures in the article can be found online at www.tandfonline.com/wasr.

${ }^{1}$ For ethical reasons, the name of the airport is not revealed.

(C) 2017 Taylor \& Francis Group, LLC 
2012; Ramos et al., 2012; Weiss et al., 2016). This means that it is a challenge to associate the "real" causes of fear while in transit. This is particularly true for airports, where most places are unfamiliar, as most individuals not fly on an everyday basis.

Yet, what still can be done is to ask individuals about their perceptions retrospectively, at particular environments and assume that their answers reveal passengers' experiences and judgements about those particular environments and their declared safety. Thus, the term "perceived safety" is used here as a general concept that characterizes one's declared feelings of anxiety and/or fear along a trip. We do not claim clear cut causality between environmental conditions and declared safety. Instead, we assume that if different environments affect passengers differently, then this evidence is enough to demand actions that lead to an improvement of these places. This means that the term "perceived safety" includes just about all possible mechanisms that lead passengers to declare that they are either satisfied or unsatisfied with their safety.

Perceived safety is prompted by overall comfort at a particular spot (check points, noise, cameras) or triggered by the quality of services (waiting time, personal treatment); it can also be generated by tangible but less likely risks, such being a victim of crime or caught in an act of terrorism. Thus, the environments to which an individual is exposed to along the trip are key since they constitute "the triggers" to passenger's declared safety, whether or not these triggers offer any real risk. The complexity of safety in transit environments has long been illustrated by studies looking at a variety of transit environments: railway systems, bus stops, transit hubs, underground stations (Ceccato, 2013; Ceccato \& Newton, 2015; LaVigne, 1997; Loukaitou-Sideris, 2012; Newton, 2008; Newton, Johnson, \& Bowers, 2004; Smith \& Cornish, 2006). Yet, little is known about perceived safety in airports. The literature also lacks evidence of the effect of passenger's choices of modes of transport on their overall perceived safety.

The aim of this article is to report on patterns of passenger's satisfaction with their perceived safety in an airport. This is achieved by:

1. Identifying which are the environments that trigger poor perceived safety at airports.

2. Assessing whether passengers' perceived safety is associated with perception of airport environments, on passengers' status (i.e., departing and arriving at the airport), and way of traveling to the airport.

3. Evaluating how much of the variation of passengers' perceived safety is explained by airport environments, everything else remaining equal.

The study is based on an analysis of a unique database of passenger surveys (from January 2014 to September 2015, N = 1218) at a European airport using Chi-square analysis and binary logistic regression. The structure of this article is as follows. First, the relevant literature on the relationship between environment and perceived safety is reviewed, then the main hypotheses of the study are stated. The study area is then framed, followed by a presentation of data and methods. Results, a discussion of results, and conclusions are then presented, and the article closes with some implications of the results for both research and practice. 


\section{Perceived safety at airports: Theory and hypotheses}

A passenger's declared perceived safety at an airport depends on multiscale environmental and temporal factors that start when the passenger leaves home for the airport or when he or she lands when returning from a trip (Aghahowa \& Stephen, 2007; Dale \& Brian, 2007; Molotch, 2012; Sindhav, Holland, Rodie, Adidam, \& Pol, 2006).

Although airports vary by size (e.g., international vs. domestic), location (e.g., intraurban vs. outskirts), design and type (e.g., modern, see-through walls), they follow some basic standards. All airports have entrances and exits, lobbies, security checkpoints, basic facilities (e.g., toilets, medical assistance, guard patrol offices), social areas with restaurants and shops, transition areas (e.g., stairs, elevators, spaces between gates or terminals), and waiting areas at gates. Yet, there is a need to better understand how the arrangements and maintenance of these parts (and services provided in them) impact on passengers' perceived safety. Traditionally, passengers' perceived safety is considered to be a function of how well airport personnel perform their duties (screeners, security guards, and ground personnel). In terms of security services, Kirschenbaum and Rapaport (2014) found, for example, that personnel with more training comply with protocols and rules more than those with less training do. Security checkpoints may also be a source of stress which is accepted for the sake of overall safety (Kirschenbaum, 2013; Oliveira, Ferrer, \& Parasuraman, 2012).

Research in transit crime has also shown that the physical characteristics of transit environments (e.g., lighting, floor separations, security hardware) are associated with perceived safety. Researchers argue that safety directly or indirectly relates to the visibility of passengers, the possibilities to be seen and to see others (for a review, see Ceccato \& Newton, 2015). Equally, well-maintained facilities provide an indication that personnel of the airport have everything under control. Clearly visible lobbies, overpass walkways for the overview, and separation of passenger flows have been shown to be factors positively affecting safety in transit nodes (Ceccato, 2013; Gaylord \& Galliher, 1991; LaVigne, 1997; Myhre \& Rosso, 1996). Transportation sites such as airports may often be crowded but lack capable guardians-people who, sometimes just by their presence, discourage crime or other unpleasant events from taking place (Cohen \& Felson, 1979). However, the capacity of passengers to intervene is often overestimated. Travelers, who might be considered informal guardians, often have no sense of ownership while in transit. They might be unwilling to get involved in places like an airport as they are "in a hurry" (completely focused on getting to their destination/gate) or they do not feel any attachment to the other passengers at the airport. Therefore, the existence of nearby potential controllers or guardians does not necessarily guarantee surveillance at airports. Statistics on crime at international airports show that thefts from baggage carousels, swiped property left unattended (especially laptops and iPads), and thefts by baggage handlers are common (Los Angeles Airport Police, 2015; New York Post, 2011; Figure 1). For the effect of these "uncertainties" and potential "threats" along the trip on passenger's overall anxiety, see Molotch (2012). 


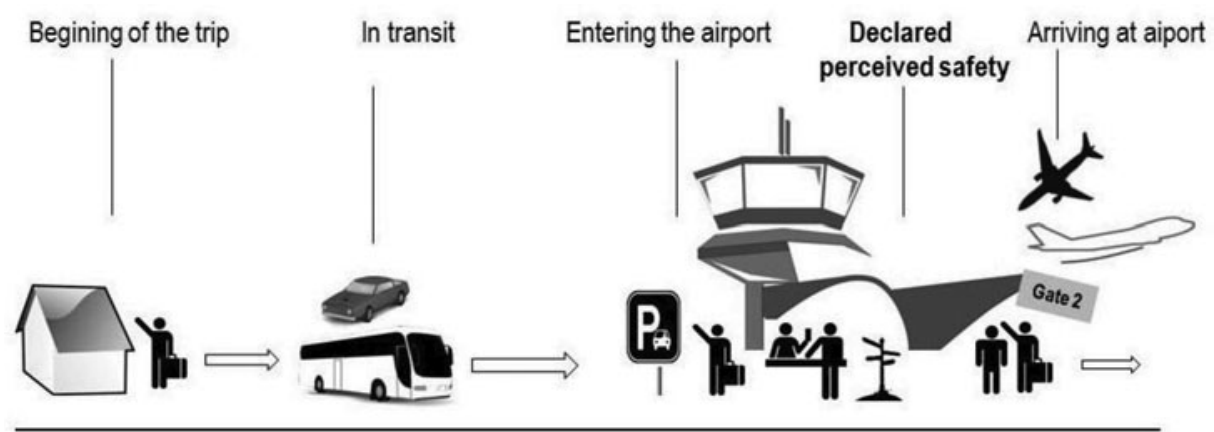

Figure 1. Perceived safety by passengers at airports: A tentative conceptual framework.

Declared perceived safety is also affected by the way a passenger gets to or from the airport and what happens en route, either from home or from an incoming flight. Harvey (1986) showed that travel time and cost were the most important factors influencing the choice of airport access mode for passengers in one North American airport. Gupta, Vovsha, and Donnelly (2008) found that passenger travel behavior to the airport is significantly different for business and nonbusiness travelers. They also found that taxis and shared vans were favored when traveling to airports with a higher number of flights, and local bus/coach service was favored when traveling to airports with a higher number of domestic flights. Different types of passengers might have different preferences. For instance, Chang (2013) found that elderly passengers were less likely to use public transport when going to the airport because they did not feel as safe as they did by other means. His results also indicated that "safety" was the most important factor in choice of access mode (preferring to ask family members to drive them to the airport, while general passengers prefer to take a taxi). Yet, many crimes happen outside the main terminals, often in parking lots and where goods are parked in transit (Los Angeles Airport Police, 2015). Crime statistics at airports often cover large areas, including passenger terminals, parking facilities, aircraft ramps, offices, and cargo areas, but may often miss what happens when passengers are in transit, from home to the airport, or in flight, on their journey in the air. For instance, at Los Angeles Airport, which has its own special police force, statistics show miscellaneous crimes at parking lots are common, followed by thefts, burglary, and physical damage (Los Angeles Airport Police, 2015).

This study builds on the current studies on safety and security issues in airports (see, for instance, Kirschenbaum \& Rapaport, 2014; Lum et al., 2015; Oliveira et al., 2012; Patankar \& Holscher, 2000) and is informed by the traditional literature that associates perceived safety with passengers' individual characteristics and environmental features of places, more specifically of transit environments (Box, Hale, \& Andrews, 1988; Ceccato, Uittenbogaard, \& Bamzar, 2013; Clarke, 2012; Garofalo \& Laub, 1979; Jeffery, 1977; Lagrange \& Ferraro, 1989; Loukaitou-Sideris, 2012; Newman, 1972; Warr, 1985; Whitzman, 2007). Thus, the declared perceived safety is expected to be affected by the individual attributes of each passenger (e.g., age, gender, ethnic affiliation). 
For the purposes of this case study, we follow the recent strand of Western research on perceived safety and we expect that apart from individual characteristics of passengers (e.g., age, gender), passengers' declared satisfaction with safety at airports is determined by (a) the quality of the physical and social indoor environment, including facilities and services they may offer and the immediate outdoor areas (parking and arrival areas), and (b) the transit environments that passengers are exposed to while in transit, either departing or arriving at the airport.

1. Passengers' declared safety varies across different environments of the airport. Declared safety at security checkpoints is for instance lower than elsewhere.

2. The satisfaction with the airport's physical and social environment (e.g., perception of services at security checkpoints, maintenance of facilities) experienced by passengers is expected to be associated with the overall declared safety at the airport.

3. Similarly, the status of the passenger (departing or arriving at the airport) is expected to be associated with patterns of passengers' satisfaction with their safety at the airport. The mode of travel to the airport is expected to affect the declared satisfaction with safety at the airport. Those using public transportation modes, because of the risks they might be exposed to during the trip, are expected to declare less satisfaction with their safety than those arriving at the airport in vans, taxis, or private cars.

4. It is expected that the variation of passengers' perceived safety is affected by characteristics of passengers, everything else remaining equal.

\section{Study area}

The studied airport presents an interesting case. First, it is one of the most important European regional airports with 7.5 million passengers per year. The airport is approximately six kilometers of the town center, so compared to the average for other European airports; it is close to the urban center. The airport is increasing, and this expansion has allowed the opening of new commercial activities and also new passenger-oriented services. Second, passengers can arrive by their own car, taxi, or public transportation. There is a direct scheduled coach service for customers that connects the airport with the city center and the railway station. Third, the airport is committed to reach a series of quality standards, including quality of the environment. As part of their commitment to this goal, the airport collects information about passenger satisfaction every three months, a dataset that made this analysis possible.

\section{Data and methods}

The survey data used in this study has been gathered by a specialized data collection company, which collects data in order to assess the quality of the airport in terms of regularity of the service, cleanliness, and comfort of spaces, and information to 
passengers. It is based on a random but representative sample of passengers before embarking/alighting. The data collection last one week, including Saturdays and Sundays. The time of interviews is variable, from 6 a.m. to 9 p.m. depending on the flights that has to be sampled. The available dataset is an output of seven survey sets, covering the period from January 2014 to September 2015, comprising a total of 3,859 passengers. The survey is composed of three sets of questions. The first set of questions is about the profile of the passenger (age, gender, nationality, education, profession, home country, number of companions, state of the trip, means of transport to reach the airport, airline, destination, number of flights per year). The second set of questions refers to the use and perception of the environment of the airport and experience with the facilities, checkpoints, information, and quality of services. The third set of questions is devoted to the way the passenger arrived at the airport and the perception of the passenger on the premises of the airport while in transit (in a bus or parking lot). This dataset was complemented by another survey conducted in December 2015, consisting of two questions about which places travelers judged as more problematic in terms of safety at the airport. Answers to the complementary questions were also incorporated into this analysis.

The dataset was imported into SPSS ${ }^{2}$ after a process of data cleaning using spreadsheets. SPSS was used to organize, recategorize, and relabel the data into new variables. A preanalysis consisted in running frequency analysis to identify any inconsistencies in the data. The main variable (perceived safety) used in this analysis is on a scale from 1 to 10 , from awful to excellent, reflecting the passenger's perceived safety and safety of his/her belongings in the airport (How do you judge your safety and of your belongings in the airport?). Since most passengers declared feeling satisfied with their safety, a dichotomous variable (Satisfied/Not satisfied) was created. Many variables were also modified in an attempt to reduce the number of categories. A summary of the variables used in the analysis is shown in Appendix.

Cross tabulation using Chi-square tests enabled comparisons between distributions of two or more variables (e.g., differences between men and women in satisfaction with services at checkpoints). "The Chi-square test gives a criterion for verifying, on probabilistic grounds, the consistency of a theoretical hypothesis with a set of experimental data" (Fornasini, 2009, p. 193). Frequency analysis provided the direction of possible relationships between the variables. Although cross tabulation does not show causality, this analysis was fundamental to identify the main trends in the data and help select questions from the survey to be the independent variables in the regression models.

In order to evaluate how much of the variation of passengers' perceived safety is explained by airport environments, everything else remaining equal, a binary logistic regression analysis was performed (The dependent variable was the dichotomous variable, whether the passenger was satisfied with his/her safety $=1$, or otherwise $=0$ ). Logistic regression is well suited for describing and testing hypotheses about relationships between a categorical outcome variable and one

\footnotetext{
${ }^{2}$ SPSS v. 23. However any standard statistical package would be suitable for this analysis.
} 
or more categorical or continuous predictor variables (Peng et al., 2002). The literature supports the use of a logistic regression model when aiming to evaluate customer satisfaction, whose information is usually collected through categorical responses (e.g., Lawson \& Montgomery, 2006). For simplicity, let us imagine only one explanatory variable $\mathrm{X}$ and the selected dependent variable $\mathrm{Y}$. The regression equation of $\mathrm{Y}$ on $\mathrm{X}$, using a logistic function, assumes the following form:

$$
P(Y=1 \vee X)=\frac{e^{\alpha+\beta x}}{1+e^{\alpha+\beta x}}
$$

where $\mathrm{P}(\mathrm{Y}=1 \mid \mathrm{X})$ represents the probability that $\mathrm{Y}=1$ given $\mathrm{X}$, the value(s) of pre$\operatorname{dictor}(\mathrm{s}), \alpha$ is the $\mathrm{Y}$ intercept, and $\beta$ is the regression coefficient. $\mathrm{Y}=1$ means that we are referring to the probability of success, namely the passenger's satisfaction with safety at the airport. The set of independent variables revealed the characteristics of the environment of the airport and experience of services, transportation to the airport, and individual characteristics of the traveler. The dependent variable was constituted by those who answered the question: How do you judge your safety and of your belongings in the airport? To assess the robustness of the results across different models and types of passengers, we adopted two modeling strategies. First, we modeled the total sample, the "full model," which includes all passengers (both arriving and departing) while in the second modeling strategy, data on departing passengers, which constitutes more than half of the sample, was split into male and female.

\section{Results}

\section{Places that trigger poor perceived safety at airports}

Among an independent sample of 400 travelers, toilets are pointed out as places that trigger feelings of worry and anxiety about their safety, including their belongings (Figure 2(a)), after airport entrances, security checkpoints, and boarding areas. Among those $21 \%$ of passengers who pointed out problematic places at the airport, about half of them suggested feelings of confusion, especially at airport entrances. Security check points, boarding areas, restaurants, and shops are also mentioned as places where they feel anxious or less safe.

Additionally, some travelers complain about poor signage, confusion, and noisy and poorly lit places in certain parts of the airport; these factors all negatively affect access to information (Figure 2(b)). Figure 3 illustrates the security checkpoints and bus stop area at the airport.

\section{Association between passengers' perceived quality of airport environments and declared safety}

Results from cross tables and Chi-square analysis show significant associations between the total travelers' declared perceived safety and almost all factors that characterize a passenger's experience with the airport (important to note that these 


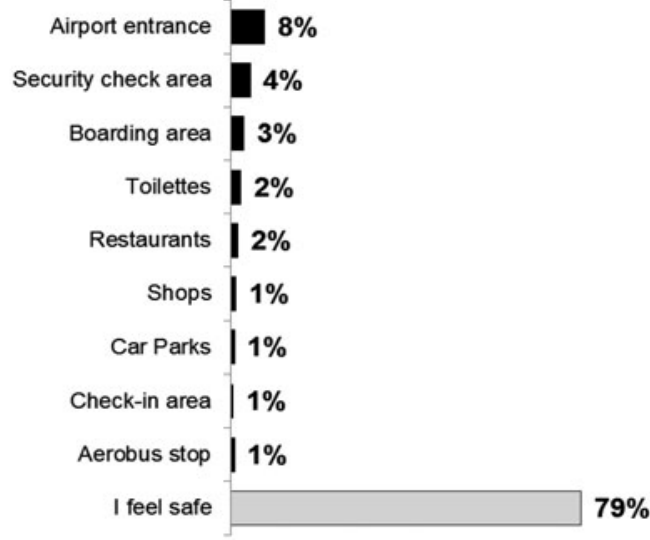

Is there a place in the airport that make you feel uncomfortable, worried about your personal belongings, anxious or fearful? $(\mathrm{N}=400)$

(a)

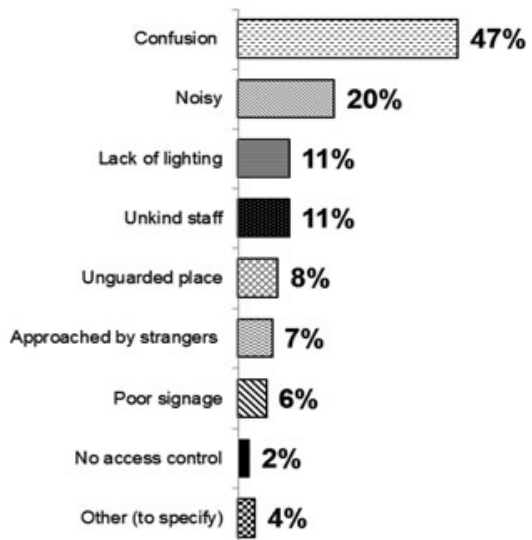

Why do you declare feeling unsafe in that/those place $(\mathrm{s})$ ? $(\mathrm{N}=83)$

(b)

Figure 2. Perceived safety at airport places (a) and reasons for feeling unsafe (b).
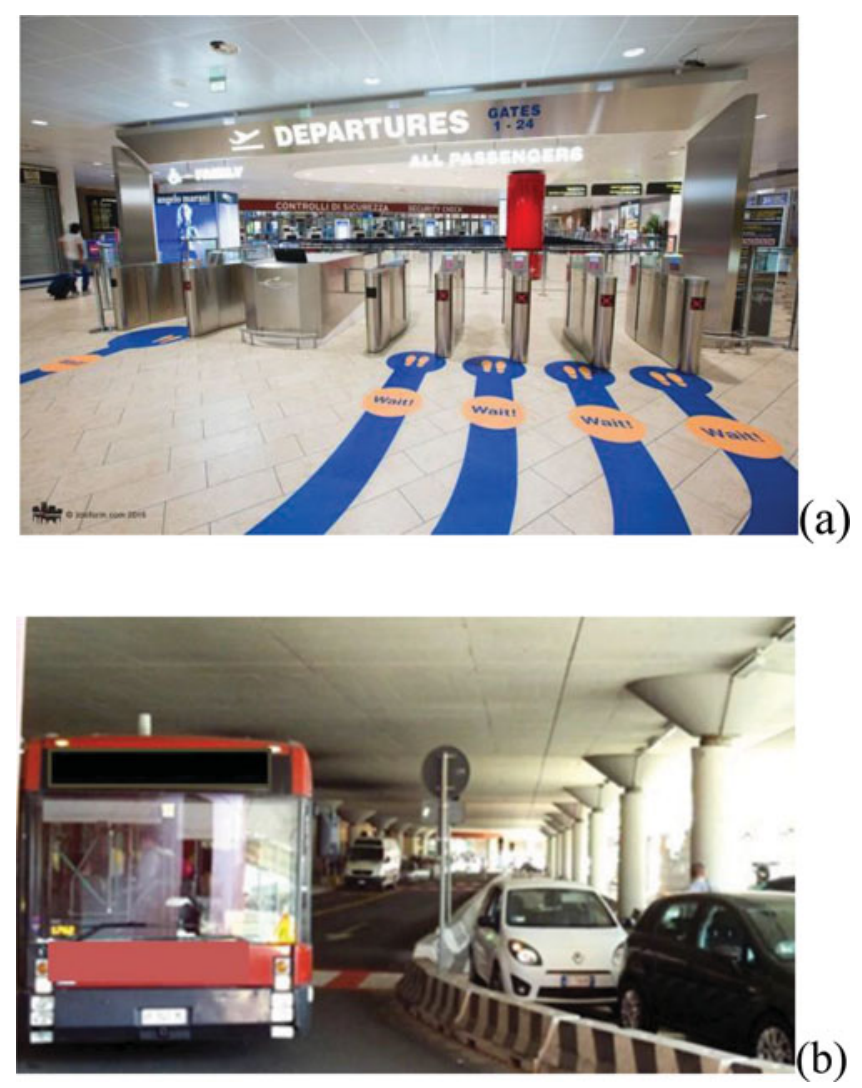

Figure 3. Security checkpoints (a) and bus at airport entrance (b). 
tests are not indicative of causality). As follows, we discuss these associations in more detail.

Good illumination $\left(\chi^{2}=808.333, \mathrm{df}=2, \mathrm{p}<0.00\right)$; silent places $\left(\chi^{2}=822.550\right.$, $\mathrm{df}=2, \mathrm{p}<0.00)$; air-conditioned environments $\left(\chi^{2}=740.179, \mathrm{df}=2, \mathrm{p}<0.00\right)$; efficient passenger-transfer systems, such as escalators or elevators $\left(\chi^{2}=784.915\right.$, $\mathrm{df}=2, \mathrm{p}<0.00$ ); are together helpful for making passengers feel safer. Yet, many passengers declare higher levels of perceived safety when they are simultaneously satisfied with the overall cleanliness of the airport $\left(\chi^{2}=835.653, \mathrm{df}=2, \mathrm{p}<0.00\right)$ and its maintenance conditions $\left(\chi^{2}=961.262, \mathrm{df}=2, \mathrm{p}<0.00\right)$. Among other airport services, toilets are worth mentioning. There is a relationship between passengers' perception of safety and some characteristics of toilets, such as cleanliness $\left(\chi^{2}=343.375, \mathrm{df}=2, \mathrm{p}<0.00\right)$ and maintenance $\left(\chi^{2}=317.536, \mathrm{df}=2, \mathrm{p}<0.00\right)$. Passengers declared more satisfaction when they experienced good toilet functionality $\left(\chi^{2}=436.012, \mathrm{df}=2, \mathrm{p}<0.00\right)$ and a good supply of toilets in the various airport areas $\left(\chi^{2}=388.087, \mathrm{df}=2, \mathrm{p}<0.00\right)$ (It is important to note that many passengers did not answer the questions about toilets.). What emerges in these results is also a high level of association between how one declares feeling safe and the access to overall information at the airport $\left(\chi^{2}=742.037, \mathrm{df}=2, \mathrm{p}<0.00\right)$. Thus, travelers feel safe with efficient info points $\left(\chi^{2}=751.274\right.$, df $\left.=2, \mathrm{p}<0.00\right)$, clear info messages, $\left(\chi^{2}=750.238, \mathrm{df}=2, \mathrm{p}<0.00\right)$, understandable signage $\left(\chi^{2}=802.816, \mathrm{df}=\right.$ $2, \mathrm{p}<0.00)$, and information on monitors $\left(\chi^{2}=778.516, \mathrm{df}=2, \mathrm{p}<0.00\right)$. For the sample of departing and arriving passengers, results are in general very similar to the overall sample. However, for departing passengers, findings reveal that airport security checks have a significant impact on their perception of safety, in some cases positive $\left(\chi^{2}=874.513, \mathrm{df}=2, \mathrm{p}<.00\right)$, in others, negative. For instance, as many as $68 \%$ of passengers that report being dissatisfied with their perceived safety are also unhappy with the efficacy or quality of security inspections. Jointly, the courtesy $\left(\chi^{2}=493.424, \mathrm{df}=2, \mathrm{p}<0.00\right)$ and competence $\left(\chi^{2}=637.813, \mathrm{df}=2, \mathrm{p}<0.00\right)$ of security staff affect the individual perception, often positively.

The declared perceived safety at the airport is also associated with travelers' experiences prior to their arrival at the airport (Figure 4). Note that about $30 \%$ of travelers come by airport coach. The way they arrive at the airport affects their declared perception of safety at the airport $\left(\chi^{2}=32.209\right.$, df $\left.=1, \mathrm{p}<0.00\right)$. Passengers using public transportation to go to the airport, for instance, report a lower level of satisfaction with their safety than those using cars. Bus users report high levels of dissatisfaction and complain about crowded conditions on the bus in route to the airport $\left(\chi^{2}=12.609, \mathrm{df}=1, \mathrm{p}<0.00\right)$. Other aspects that have a negative impact on traveler's perceived safety are the frequency of bus departures $\left(\chi^{2}=325,040\right.$, $\mathrm{df}=1, \mathrm{p}<0.00)$ and problems with the punctuality of public transportation overall $\left(\chi^{2}=344.483, \mathrm{df}=1, \mathrm{p}<0.00\right)$. Regarding car users, several characteristics of car parks are important to explain this choice of transport, such as sufficient capacity of car parks $\left(\chi^{2}=93.266, \mathrm{df}=1, \mathrm{p}<0.00\right)$, short distance to the airport $\left(\chi^{2}=\right.$ $123.038, \mathrm{df}=1, \mathrm{p}<0.00)$, good accessibility and clear signage $\left(\chi^{2}=82.736, \mathrm{df}=\right.$ $1, \mathrm{p}<0.00)$, and staff's courtesy and competence $\left(\chi^{2}=75.317, \mathrm{df}=1, \mathrm{p}<0.00\right)$. 


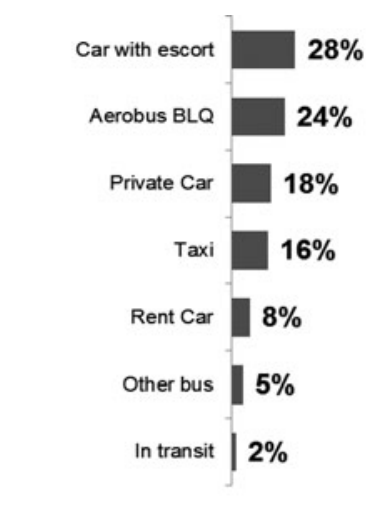

How did you arrive at the airport today?" $(\mathrm{N}=400)$

(a)

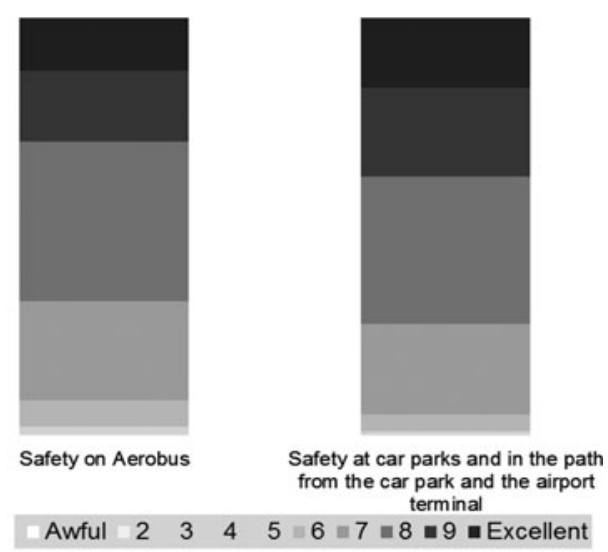

How do you judge your safety in ...? $(\mathrm{N}=400)$

(b)

Figure 4. Access to the airport by mode (a) and perceived safety (b).

Finally, several interesting findings are worth highlighting for this sample of passengers. The international literature shows that women declare more often than men do, that they are less satisfied with their safety in transit environments. However, for this particular sample of passengers, this is not the case. Male passengers are often more critical about their safety than female travelers are $\left(\chi^{2}=13,736, \mathrm{df}=\right.$ $1, \mathrm{p}<0.00)$. Another unexpected result is about passenger age and safety: perceived safety increases with age $\left(\chi^{2}=7.304, \mathrm{df}=2, \mathrm{p}=0.01\right)$. Elderly passengers $(>$ 55 years old) tend to declare feeling safer than younger groups of passengers (14-34 and 35-54). Nationality (Native/no native passengers) seems to be ineffective to explain safety $\left(\chi^{2}=0.042, \mathrm{df}=1, \mathrm{p}=0.837\right)$, while the level of education increases the passenger's anxiety $\left(\chi^{2}=9.095, \mathrm{df}=2, \mathrm{p}=0.011\right)$. Actually, $74 \%$ of passengers with lower levels of education report satisfaction with their safety, while only $66 \%$ of passengers with an advanced education share that opinion. Passengers traveling alone are surely the most satisfied in terms of perceived safety $\left(\chi^{2} 113.093, \mathrm{df}=2\right.$, $\mathrm{p}<0.00$ ), reaching $74 \%$. The percentage of satisfaction sharply decreases, to $56 \%$, when passengers are traveling in a group of three or more people. Results show that high-frequency air travelers feel more comfortable in the airport environment $\left(\chi^{2}=\right.$ 47.442 , $\mathrm{df}=1, \mathrm{p}<0.00$ ), and, moreover, when a passenger has previously visited the airport, the difference between satisfied and not satisfied is even more evident $\left(\chi^{2}=122.605, \mathrm{df}=1, \mathrm{p}<0.00\right)$. Interestingly, the more time a passenger spends in the airport terminal before the security check, the higher is his or her feeling of safety $\left(\chi^{2}=35.269, \mathrm{df}=2, \mathrm{p}<0.00\right)$. Satisfaction decreases as time decreases: $78 \%$ are happy if they have more than $1 \mathrm{hr}$ there, 64\% if they spend between 30 and $60 \mathrm{~min}$ before the checkpoints. Allowing passengers to calmly fulfil the flight requirements before the security checks affect their overall perceived safety. Moments of anxiety and confusion at the entrance of the airport can be mediated by arriving at the 
airport in good time. Although we are not claiming any causality, these associations are worth noting before we start the hypothesis testing in the next section.

\section{Modeling the impact of airport environments on the variation of passengers' overall perceived safety}

We modeled passenger satisfaction with perceived safety in the airport as a function of passenger perceptions of the environmental attributes of the airport, controlling for individual characteristics and the conditions along the trip, following the conceptual model shown in Figure 1. To assess the robustness of the results across different models and types of passengers, we adopted two modeling strategies: the "full model" strategy, which includes all passengers (both arriving and departing, Table 1) and the second modeling strategy, includes data on departing passengers, which constitutes the more than half of the sample, was split into male and female (Table 2).

Passengers who say they are happy with the overall maintenance and cleanliness of the airport are twice as likely to declare themselves satisfied with their safety and their belongings at the airport. These variables are also significant for departing passengers (Table 1). As many as 11 out of 14 variables concerning the environmental attributes of the airport were significant to explain passenger satisfaction with their safety. These attributes are noise levels/silence, air conditioning, cleanliness, monitors, recorded messages, signage, elevators and escalators, and overall maintenance.

As expected, for arriving passengers individual characteristics are more important to explain their overall declared safety than are the airport's environmental features (age, whether the passenger is accompanied, frequency of travel, whether the passenger has previously been at this airport). Departing passengers, who have more time to experience the airport, are most certainly more influenced by the environment of the airport than those arriving (for this arriving group, only five variables are significant out of 14). Yet, regardless whether they are arriving or departing, women are more perceptive of the airport environment than men are (10 significant variables for female passengers, and only six for male passengers). There are interesting gender differences. For instance, for an additional woman who declares dissatisfaction with the air conditioning, the odds of having her declare satisfaction with her safety decrease by $35 \%$; a similar percentage is found for satisfaction with the message system among women. Interestingly, these two factors (air conditioning and recorded messages) do not matter to male passengers. For an additional individual who declares dissatisfaction with the maintenance of toilets, the odds of having the passenger declare satisfaction with safety decrease by 43\% (38\% for men and 63\% for women, Table 2).

For passengers on departing flights, the variable most important to explain satisfaction at the airport is the variable that reflects satisfaction with security checkpoints, yet the variables reflecting the perception of the environment of the airport are also highly relevant. Departing passengers who declare satisfaction with 
Table 1. Results of the "full model"-Binary logistic regression, $Y=$ Passenger's declared satisfaction with safety.

\begin{tabular}{|c|c|c|c|c|c|c|c|c|c|}
\hline & \multicolumn{3}{|c|}{ Total sample $=3859$} & \multicolumn{3}{|c|}{$\begin{array}{c}\text { Departing } \\
\text { passengers }=2136\end{array}$} & \multicolumn{3}{|c|}{ Arriving passengers $=766$} \\
\hline & Coef. & St. Dev. & $\operatorname{Exp}(B)$ & Coef. & St. Dev. & $\operatorname{Exp}(B)$ & Coef. & St. Dev & $\operatorname{Exp}(B)$ \\
\hline \multicolumn{10}{|l|}{ Individual attributes } \\
\hline Male & -0.089 & 0.087 & 0.087 & -0.134 & 0.129 & 0.874 & -0.048 & 0.143 & 0.953 \\
\hline Age & $0.227^{* * *}$ & 0.067 & 0.067 & $0.157^{*}$ & 0.1 & 1.17 & $0.194^{*}$ & 0.116 & 1.214 \\
\hline Nationality & 0.07 & 0.096 & 0.096 & $0.322^{* * *}$ & 0.143 & 1.38 & -0.029 & 0.157 & 0.972 \\
\hline Educational level & -0.097 & 0.076 & 0.076 & -0.092 & 0.113 & 0.912 & -0.175 & 0.13 & 0.839 \\
\hline Companions & $-0.246^{* * *}$ & 0.055 & 0.055 & $-0.226^{* * *}$ & 0.083 & 0.798 & $-0.219^{* * *}$ & 0.09 & 0.803 \\
\hline $\begin{array}{l}\text { Frequency of } \\
\text { flights/year }\end{array}$ & $0.213^{* * *}$ & 0.09 & 0.09 & 0.123 & 0.133 & 1.131 & $0.253^{*}$ & 0.152 & 1.288 \\
\hline $\begin{array}{l}\text { Familiarity } \\
\text { Environment attributes }\end{array}$ & $0.725^{* * *}$ & 0.117 & 0.117 & $0.651^{* * *}$ & 0.183 & 1.918 & $0.415^{* * *}$ & 0.184 & 1.514 \\
\hline Well lit & 0.087 & 0.1 & 1.062 & -0.098 & 0.156 & 0.907 & -0.017 & 0.159 & 0.983 \\
\hline Silent & $0.067^{* *}$ & 0.097 & 1.222 & $0.217^{*}$ & 0.152 & 1.242 & $0.267^{*}$ & 0.153 & 1.306 \\
\hline Air conditioning & $0.096^{* * *}$ & 0.095 & 1.224 & -0.088 & 0.151 & 0.916 & 0.16 & 0.152 & 1.173 \\
\hline Cleanliness & $0.076^{* * *}$ & 0.102 & 2.059 & $0.556^{* * *}$ & 0.15 & 1.744 & 0.943 & 0.169 & 2.568 \\
\hline Overall maintenance & $0.055^{* * *}$ & 0.099 & 2.215 & $0.448^{* * *}$ & 0.146 & 1.565 & 0.892 & 0.162 & 2.439 \\
\hline Signage & $0.09^{* * *}$ & 0.098 & 1.307 & 0.126 & 0.162 & 1.134 & 0.164 & 0.141 & 1.178 \\
\hline Recorded messages & $0.117^{* * *}$ & 0.07 & 1.3 & $0.357^{* * *}$ & 0.113 & 1.428 & 0.035 & 0.11 & 1.036 \\
\hline Monitors & $0.258^{* * *}$ & 0.098 & 1.294 & $0.335^{* *}$ & 0.163 & 1.398 & $0.267^{* *}$ & 0.142 & 1.306 \\
\hline Overall information & 0.069 & 0.102 & 1.072 & -0.055 & 0.166 & 0.947 & 0.076 & 0.152 & 1.079 \\
\hline $\begin{array}{l}\text { Elevators and } \\
\text { Escalators }\end{array}$ & $0.253^{* * *}$ & 0.061 & 1.288 & $0.452^{* * *}$ & 0.117 & 1.572 & $0.176^{* *}$ & 0.087 & 1.193 \\
\hline \multicolumn{10}{|l|}{ Toilets: } \\
\hline Availability & 0.049 & 0.143 & 1.05 & $0.326^{*}$ & 0.191 & 1.385 & $-0.662^{* *}$ & 0.3 & 0.516 \\
\hline Functionality & $0.203^{*}$ & 0.141 & 1.225 & 0.111 & 0.188 & 1.117 & 0.133 & 0.282 & 1.142 \\
\hline Cleanness & $0.193^{*}$ & 0.129 & 1.213 & 0.152 & 0.172 & 1.165 & $0.482^{* *}$ & 0.25 & 1.62 \\
\hline $\begin{array}{c}\text { Maintenance } \\
\text { Experience services }\end{array}$ & $-0.507^{* * *}$ & 0.153 & 0.602 & $-0.571^{* * *}$ & 0.201 & 0.565 & -0.122 & 0.303 & 0.885 \\
\hline $\begin{array}{l}\text { Security Check Points: } \\
\text { Security Inspections }\end{array}$ & - & - & - & $1.271^{* * *}$ & 0.129 & 3.565 & - & - & - \\
\hline Courtesy & - & - & - & -0.17 & 0.156 & 0.844 & - & - & - \\
\hline Competence & - & - & - & $0.353^{* *}$ & 0.163 & 1.424 & - & - & - \\
\hline Waiting Time & - & - & - & $0.685^{* * *}$ & 0.125 & 1.983 & - & - & - \\
\hline \multicolumn{10}{|l|}{ Before check points } \\
\hline $\begin{array}{l}\text { Time before } \\
\text { inspections }\end{array}$ & - & - & - & -0.118 & 0.096 & 0.889 & - & 一 & 一 \\
\hline $\begin{array}{l}\text { Transport from/to } \\
\text { airport }\end{array}$ & - & - & - & -0.151 & 0.126 & 0.86 & - & - & - \\
\hline Nagelkerke R Square & 0.352 & & & 0.487 & & & 0.318 & & \\
\hline Cox \& Snell R Square & 0.251 & & & 350 & & & 0.224 & & \\
\hline (sig) & 3719.394 & & & 1787.481 & & & 1321.563 & & \\
\hline
\end{tabular}

*Significant at $10 \%$ level. **Significant at $5 \%$ level. *** Significant at $1 \%$ level.

the security check practices are at least three times more likely to declare satisfaction with their safety and their belongings at the airport (especially women, who are four times more likely). They tend to be satisfied with waiting times at checkpoints and competence of the personnel.

The model indicates that passengers who do not travel alone tend to declare less satisfaction with their safety at the airport than those who fly by themselves. For one additional person the passenger adds as a companion, the odds of having the passenger satisfied with safety decrease $20 \%$ (Table 1), and as it regards departures, 
Table 2. Results-Binary logistic regression, $Y=$ Passenger's declared satisfaction with safetyDeparting passengers by gender $(\mathrm{N}=2136)$.

\begin{tabular}{|c|c|c|c|c|c|c|}
\hline & \multicolumn{3}{|c|}{ Male $=1335$} & \multicolumn{3}{|c|}{ Female $=801$} \\
\hline & Coef. & St. Dev. & $\operatorname{Exp}(B)$ & Coef. & St. Dev. & $\operatorname{Exp}(B)$ \\
\hline \multicolumn{7}{|l|}{ Individual attributes } \\
\hline Male & - & - & - & - & - & - \\
\hline Age & -0.038 & 0.134 & 0.963 & $0.336^{* *}$ & 0.161 & 1.399 \\
\hline Nationality & 0.426 & 0.186 & 1.531 & 0.319 & 0.236 & 1.376 \\
\hline Educational level & -0.12 & 0.147 & 0.887 & -0.083 & 0.19 & 0.921 \\
\hline Companions & $-0.262^{*}$ & 0.107 & 0.769 & -0.179 & 0.139 & 0.836 \\
\hline $\begin{array}{l}\text { Frequency of } \\
\text { flights/year }\end{array}$ & 0.119 & 0.164 & 1.127 & 0.114 & 0.24 & 1.121 \\
\hline Familiarity & $0.737^{* * *}$ & 0.23 & 2.089 & $0.582^{* *}$ & 0.317 & 1.789 \\
\hline \multicolumn{7}{|l|}{ Environment attributes } \\
\hline Well lit & -0.046 & 0.201 & 0.955 & -0.227 & 0.269 & 0.797 \\
\hline Silent & 0.119 & 0.195 & 1.126 & $0.4^{*}$ & 0.26 & 1.492 \\
\hline Air conditioning & 0.043 & 0.194 & 1.043 & $-0.421^{*}$ & 0.264 & 0.656 \\
\hline Cleanliness & $0.452^{* * *}$ & 0.192 & 1.571 & $0.784^{* *}$ & 0.26 & 2.189 \\
\hline Overall maintenance & $0.51^{* * *}$ & 0.192 & 1.666 & $0.352^{*}$ & 0.243 & 1.422 \\
\hline Signage & -0.07 & 0.202 & 0.933 & $0.474^{*}$ & 0.291 & 1.607 \\
\hline Recorded messages & $0.72^{* * *}$ & 0.145 & 2.055 & $-0.353^{*}$ & 0.206 & 0.703 \\
\hline Monitors & 0.232 & 0.21 & 1.261 & $0.531^{* *}$ & 0.275 & 1.7 \\
\hline Overall information & -0.031 & 0.212 & 0.97 & -0.055 & 0.286 & 0.947 \\
\hline $\begin{array}{l}\text { Elevators and } \\
\text { Escalators }\end{array}$ & $0.405^{* * *}$ & 0.15 & 1.499 & $0.592^{* * *}$ & 0.202 & 1.807 \\
\hline \multicolumn{7}{|l|}{ Toilets: } \\
\hline Availability & 0.185 & 0.255 & 1.204 & $0.708^{* *}$ & 0.316 & 2.03 \\
\hline Functionality & $0.355^{*}$ & 0.247 & 1.427 & -0.112 & 0.311 & 0.894 \\
\hline Cleanness & -0.055 & 0.22 & 0.946 & 0.36 & 0.294 & 1.43 \\
\hline Maintenance & $-0.465^{*}$ & 0.262 & 0.628 & $-0.976^{* * *}$ & 0.346 & 0.377 \\
\hline \multicolumn{7}{|l|}{ Experience services } \\
\hline Security check points: & & & & & & \\
\hline Security inspections & $1.274^{* * *}$ & 0.166 & 3.574 & 1.404 & 0.222 & 4.072 \\
\hline Courtesy is good & -0.212 & 0.193 & 0.809 & -0.222 & 0.282 & 0.801 \\
\hline Competence is good & $0.42^{* *}$ & 0.201 & 1.521 & 0.265 & 0.295 & 1.303 \\
\hline Waiting time is good & $0.741^{* * *}$ & 0.158 & 2.098 & $0.751^{* * *}$ & 0.218 & 2.12 \\
\hline \multicolumn{7}{|l|}{ Before check points } \\
\hline $\begin{array}{l}\text { Time before } \\
\text { inspections }\end{array}$ & $-0.237^{* *}$ & 0.128 & 0.789 & 0.062 & 0.156 & 1.064 \\
\hline $\begin{array}{l}\text { Transport from/to } \\
\text { airport }\end{array}$ & -0.166 & 0.16 & 0.847 & -0.15 & 0.219 & 0.86 \\
\hline Nagelkerke R Square & 0.352 & & & 0.487 & & \\
\hline Cox \& Snell R Square & 0.251 & & & 350 & & \\
\hline (sig) & 3719.394 & & & 1787.481 & & \\
\hline
\end{tabular}

*Significant at $10 \%$ level. ** Significant at $5 \%$ level. *** Significant at $1 \%$ level.

this is a factor that affects more male passengers (23\%) than females (16\%; Table 2), so men are more sensitive when departing than arriving.

\section{Discussion of the results and recommendations}

Findings confirm hypothesis 1 , that satisfaction with the airport's environment has an impact on overall declared perceived safety (Tables 1 and 2). The airport entrance, security checkpoint areas, boarding areas, toilets, and restaurants are places where passengers declare feeling less satisfied (Figure 2). As suggested in hypothesis 3 , the airport environment has a greater effect on the perception of safety of departing 
passengers than of arriving passengers, most likely because of the difference in time spent by the two groups at the airport (the departing passengers spent more time than those who arrive).

The overall cleanliness and maintenance of the airport terminal facilities are aspects that positively contribute to passengers' perceptions of safety. A maintenance schedule is needed to avoid periods of malfunctioning or breakdown. If failure or a malfunction occurs, the time for reaction and repair should be kept to a minimum, and passengers should be properly informed. According to ACI (2014, p. 46) "elevators, escalators or moving walkways which are out of order can cause major nuisance to passengers especially when they are running out of time to reach a flight." These maintenance problems most certainly are not exclusive of airports. They cause a major stress factor in other transit environments, such as underground, railway, and bus stations.

According to our findings, passenger satisfaction with safety in airports is dependent on security checks and number of facilities and services provided at the airport. Security checks deserve particular attention because they constitute the central point of the whole "airport experience" and have different dimensions. One dimension is that security checks encompass a dramatic moment in the trip. From the passenger's perspective, security employees are "threats," while from the employees' perspective, every passenger is seen as a potential threat (Kirschenbaum, 2013). Yet, the detection process has elements of "social negotiations" for passengers and security employees, an area framed by multiple interactions between employees and passengers. The output of these interactions affects passengers' perceived safety. Another dimension of it is how routines in security checks are perceived differently within groups of passengers, for instance, by men and women. Our findings indicate that security checkpoints are more important to men's perceptions of safety than to women's (three variables significant out of four for men, and one for women, Table 2). According to Alards-Tomalin and colleagues (2014), this difference has to do with the way men and women "read" the experience at checkpoints. The author writes:

It may be that generally, men are more inclined to feel that if airport security is acting professionally, elevated screening measures will, in turn, enhance safety. Women may be less inclined to perceive this connection due to heightened concerns regarding privacy issues arising from elevated screening. (Alards-Tomalin et al., 2014, p. 66)

In addition to the importance of the availability and smooth functioning of escalators and stairs, the real-time information system in the airport is also considered relevant to passenger safety. This includes the signage that helps passengers find their way, information about restrictions on what can be carried in hand luggage, and real-time information systems that help transmit to passengers all the information necessary to keep flights on time and avoid delays. Kirschenbaum (2013) notes that airports are complex organizations, and their security routines are based on regulations that require constant training of personnel. Security staff should attend training courses to efficiently carry out their tasks and satisfy passengers' 
expectations, which are a balance between conducting operations as fast as possible without compromising the quality of checks and still fulfilling passengers' needs.

Neither for men or women, the transport mode used to travel to the airport is relevant to explain their perceived safety while women tend to be more sensitive to the quality of the environment at the airport than men do. According to Table 2 satisfaction with safety goes beyond the risk of being late for a flight because of long waits at security checkpoints. Safety is also a function of a passenger's age and familiarity with the airport environment as well as the perception of airport maintenance, availability and quality of services and facilities, and information provision. These findings highlight the need to consider safety of passengers as a multifaceted phenomenon.

The individual characteristics of passengers affect their perception of safety in the airport, as expected in hypothesis 4, but not always in the expected way. Safety is more important for men than women when traveling (Table 2) as they declare feeling less satisfied with their safety; but women are more receptive to the qualities of the airport environment to explain their perceived safety (note that eight attributes out of 10 were significant in the female model, against four attributes out of 10 for men).

Flying alone also contributes to passengers' perceived safety, particularly for men. Passengers were asked how many people they were traveling with, and in most cases findings show that the more people in a group, the less satisfied with their safety passengers declared themselves to be. Note that groups of three or more travelers are often families. This finding may be related to what Trickett (2009) calls "altruistic fear," a fear that individuals feel for other people whose safety they value. As Trickett (2009) suggests, middle-aged men "reported feeling especially vulnerable when they were out with their children and/or partners because they felt the need to protect them" (Trickett, 2009, p. 92).

\section{Conclusions and limitations}

This study set out to identify which are the environments that trigger poor perceived safety at airports. The exploratory analysis using Chi-square analysis shows significant associations between declared perceived safety and airport environments. The analysis also investigates patterns of passenger satisfaction with safety in an airport using binary logistic regression. Results using two different modeling strategies show a robust similar pattern, that passenger satisfaction with safety is affected by the passenger's perception of the airport's environment (e.g., elevators and escalators, availability and cleanliness of toilets, overall maintenance) as well as by the overall experience of being in transit, whether departing or arriving at the airport. Airport entrances, security checkpoints, boarding areas, toilets, and restaurants are places that passengers indicate as critical for their perceived safety. Results also indicate that a number of dimensions of passenger safety are gendered, namely how women and men perceive safety along the trip and particularly at check points at airport. Findings like these call for safety interventions that are sensitive to passengers' needs and adopt a whole-journey approach to safety. 
However, the analysis shares, with other analyses of the same kind, limitations that are important to point out here. One limitation is that the question that capture safety has two dimensions ("one's personal safety" and "one's property/belongings" into one question) - and, therefore, might be problematic. Thus, "personal safety" might be high but simultaneously low for perception of "luggage safety." Another limitation is that the sample size is large enough to automatically create significant Chi Squares that would might not be present for a smaller sample (type I error). Future research should not only extend the time period of analysis but also assess the importance of a time dimension on the perceived safety of passengers at the airport and throughout their journey. Of particular importance is to check seasonal, weekly, and daily variations of responses, as they may reflect very different safety conditions at the airport. Moreover, despite the fact that the study has shown evidence that the perception of the environment affects overall passengers' perceived safety, these measures are based on "perception," not actual objective indicators. Data permitting, future research should explore other environmental features that are not dependent on surveys indicators, such as numbers of uniformed security personnel, density of passenger traffic, number of available checkpoints during shifts, access to public areas.

Despite current limitations, this article makes contributions to the field of transit safety, by particularly focusing on passengers' perceived safety in airport's environments and services they provide-a topic which has so far been limited in the international literature. This study is also innovative in its attempt to explore new theoretical grounds (section 2) to support the analysis of the airport environment and passenger satisfaction with safety, by drawing on principles from environmental criminology, architecture, and engineering.

\section{References}

Aghahowa, E., \& Stephen, A. (2007). Developing key performance indicators for airport safety and securitynull. Facilities, 25, 296-315.

Alards-Tomalin, D., Ansons, T. L., Reich, T. C., Sakamoto, Y., Davie, R., Leboe-McGowan, J. P., \& Leboe-McGowan, L. C. (2014). Airport security measures and their influence on enplanement intentions: Responses from leisure travelers attending a Canadian University. Journal of Air Transport Management, 37, 60-68.

Box, S., Hale, C., \& Andrews, G. (1988). Explaining fear of crime. British Journal of Criminology, 28, 340-356.

Ceccato, V. (2013). Moving safely: Crime and perceived safety in Stockholm's subway stations. Plymouth, UK: Lexington.

Ceccato, V., \& Newton, A. (Eds.). (2015). Safety and security in transit environments: An interdisciplinary approach. Besingstoke, UK: Palgrave.

Ceccato, V., Uittenbogaard, A. C., \& Bamzar, R. (2013). Safety in Stockholm's underground stations: The importance of environmental attributes and context. Security Journal, 26, 33-59.

Chang, Y.-C. (2013). Factors affecting airport access mode choice for elderly air passengers. Transportation Research Part E: Logistics and Transportation Review, 57, 105-112.

Clarke, R. V. (2012). The theory of crime prevention through environmental design-CPTED. https://pdfs.semanticscholar.org/4a94/e72074e829aba49ff001e177870d37be13d5.pdf 
Cohen, L. E., \& Felson, M. (1979). Social change and crime rate trends: A routine activity approach. American Sociological Review, 44, 588-608.

Dale, F., \& Brian, M. (2007). Passengers' expectations of airport service qualitynull. Journal of Services Marketing, 21, 492-506.

Fornasini, P. and Harrison, D. M. (2009). The Uncertainty in Physical Measurements. American Journal of Physics, 77(9), 862.

Garofalo, J., \& Laub, J. (1979). Fear of crime-Broadening our perspective. Victomology, 3, $242-$ 253.

Gaylord, M. S., \& Galliher, J. F. (1991). Riding the underground dragon: Crime control and public order on Hong Kong's mass transit railway. British Journal of Criminology, 31, 15-26.

Gupta, S., Vovsha, P., \& Donnelly, R. (2008). Air passenger preferences for choice of airport and ground access mode in the New York City Metropolitan Region. Transportation Research Record: Journal of the Transportation Research Board, 3-11. doi: 10.3141/2042-01

Harvey, G. (1986). Study of airport access mode choice. Journal of Transportation Engineering, $112,525-545$.

Howard, W. A., Murphy, S. M., \& Clarke, J. C. (1983). The nature and treatment of fear of flying: A controlled investigation. Behavior Therapy, 14, 557-567.

Jeffery, C. R. (1977). Crime prevention through environmental design. Beverly Hills, CA: Sage.

Kirschenbaum, A. (2013). The cost of airport security: The passenger dilemma. Journal of Air Transport Management, 30, 39-45.

Kirschenbaum, A., \& Rapaport, C. (2017). Does training improve security decisions? A case study of airports. Security Journal, 30(1), 184-198. doi:10.1057/sj.2014.39

Lagrange, R. L., \& Ferraro, K. F. (1989). Assessing age and gender differences in perceived risk and fear of crime. Criminology, 27, 697-720.

LaVigne, N. G. (1997). Visibility and vigilance: Metro's situational approach to preventing subway crime. National Institute of Justice-Research in Brief. Washington, DC: U.S. Department of Justice.

Lawson, C. \& Montgomery, D. C. (2006). Logistic Regression Analysis of Customer Satisfaction Data. Quality and Reliability Engineering International, 22(8), 971-984. Available from: https://search.ebscohost.com/login.aspx?direct=true\&AuthType=cpid,ip\&custid=ns02033 $8 \& \mathrm{db}=$ eoah\&AN $=10503209 \&$ site $=$ ehost-live.

Los Angeles Airport Police. (2015). Los Angeles International Airport releases. 2014 crime statistics [Online]. Retrieved from http://www.lawa.org/AirportPolice/APDNews.aspx?id=11542

Loukaitou-Sideris, A. (2012). Safe on the move: The importance of the built environment. In V. Ceccato (Ed.), The urban fabric of crime and fear (pp. 85-100). Dordrecht, Heidelberg, New York, London: Springer.

Lum, C., Crafton, P. Z., Parsons, R., Beech, D., Smarr, T., \& Connors, M. (2015). Discretion and fairness in airport security screening. Security Journal, 28(4), 352-373. doi:10.1057/sj.2012.51

Myhre, M., \& Rosso, F. (Eds.). (1996). Designing for security in Meteor: A projected new metro line in Paris. Monsey, NY: Willow Tree.

Molotch, H. (2012). Against security: How we go wrong at airports, subways, and other sites of ambiguous danger. Princeton, NJ: Princeton University Press.

Newman, O. (1972). Defensible space-Crime prevention through urban design. New York, NY: Collier Books.

Newton, A. (2008). A study of bus route crime risk in urban areas: The changing environs of a bus journey. Built Environment (1978), 34, 88-103.

Newton, A. D., Johnson, S. D., \& Bowers, K. J. (2004). Crime on bus routes: An evaluation of a safer travel initiative. Policing: An International Journal of Police Strategies \& Management, 27, 302-319.

New York Post. (2011). Crime is soaring at Kennedy Airport [Online]. New York Post. Retrieved from http://nypost.com/2011/08/08/crime-is-soaring-at-kennedy-airport/ 
Oliveira, P. R., Ferrer, J. C. \& Parasuraman, A. (2012). Impact of delays on customers' safety perceptions and behavioral intentions. Journal of Airline and Airport Management, 2(2), 86-100.

Patankar, M. S., \& Holscher, L. (2000). Accessibility vs Security: The Challenge to Airport Security Systems. Security Journal, 13, 7-19.

Peng, C.-Y. J., Lee, K. L. and Ingersoll, G. M. (2002). An Introduction to Logistic Regression Analysis and Reporting. The Journal of Educational Research, 96(1), 3-14.

Ramos, R. T., De Mattos, D. A., Reboucas, J. T. S., \& Ranvaud, R. D. (2012). Space and motion perception and discomfort in air travel. Aviation, Space, and Environmental Medicine, 83, $1162-1166$.

Sindhav, B., Holland, J., Rodie, A. R., Adidam, P. T., \& Pol, L. G. (2006). The impact of perceived fairness on satisfaction: Are airport security measures fair? Does it matter? Journal of Marketing Theory and Practice, 14, 323-335.

Smith, M. J., \& Cornish, D. B. (2006). Secure and tranquil travel-Preventing crime and disorder on public transport. London, UK: UCL Jill Dando Institute of Crime Science.

Trickett, L. (2009). "Don't look now"-Masculinities, altruistic fear and the spectre of self: When, why and how men fear for others, crimes and misdemeanours. SOLON, 3, 82-108.

Warr, M. (1985). Fear of rape among urban women. Social Problems, 32, 238-250.

Weiss, D. J., Rosoff, R. S., Rosoff, H., Baumert, T., Buesa, M., Gomez, J., ... Roseinboim, M. (2016). Worth the risk? Terrorism-induced fear of flying. Universitas Psychologica, 15, 3.

Whitzman, C. (2007). Stuck at the front door: Gender, fear of crime and the challenge of creating safer space. Environment and Planning A, 39, 2715-2732.

\section{Appendix. The database of study}

\begin{tabular}{|c|c|c|c|}
\hline Data Type & Variable & Description & Unit \\
\hline Dependent variable & Safety & How do you judge your personal safety and of your personal belongings in the airport? & Categorical/Binary \\
\hline Independent variables/ & Gender & Gender of the passenger & Binary \\
\hline \multirow[t]{6}{*}{ Individual atributes } & Age & Age of the passenger & Categorical \\
\hline & Nationality & Nationality of the passenger & Binary \\
\hline & Education level & Level of education of the passenger & Categorical \\
\hline & Companions & Number of people that are travelling with the passenger & Categorical \\
\hline & Frequency of flights year & Number of flight per year & Categorical \\
\hline & Familiarity & Previous experience at the airpon of Bologna & Binary \\
\hline \multirow[t]{13}{*}{ Environment attributes } & Illumination & Satisfaction with airport lighting & Categorical \\
\hline & Silent & Satisfaction with level of silence & Categorical \\
\hline & Air conditioning & Satisfaction with conditioning system & Categorical \\
\hline & Cleanliness & Satisfaction with airport cleanliness & Categorical \\
\hline & Overall maintenance & Satisfaction with airport maintenance & Categorical \\
\hline & Signage & Satisfaction with airport signage & Categorical \\
\hline & Recorded Messages & Satisfaction with recorded messages & Categorical \\
\hline & Monitors & Satisfaction with informative monitors & Categorical \\
\hline & $\begin{array}{l}\text { Overall Information } \\
\text { Elevators and Escalators }\end{array}$ & $\begin{array}{l}\text { Satisfaction with simplicity to gather information } \\
\text { Satisfaction with efficiency of elevators and escalators }\end{array}$ & $\begin{array}{l}\text { Categorical } \\
\text { Categorical }\end{array}$ \\
\hline & Availability of toilettes & Satisfaction with availability of toilettes & Categorical \\
\hline & Functionality of toilettes & Satisfaction with functionality of toiletes & Categorical \\
\hline & Cleanliness of toilettes & Satisfaction with cleanliness of toilettes & Categorical \\
\hline & Overall maintenance & Satisfaction with maintenance of toilettes & Categorical \\
\hline \multirow[t]{3}{*}{ Experience services } & Security Check Points & Satisfaction with overall security check & Categorical \\
\hline & & $\begin{array}{l}\text { Satisfaction with courtesy of security staff } \\
\text { Satisfaction with competence of security staff }\end{array}$ & $\begin{array}{l}\text { Categorical } \\
\text { Categorical }\end{array}$ \\
\hline & & Satisfaction with waiting times at security gates & Categorical \\
\hline \multirow[t]{2}{*}{ Before checkpoints } & Time before inspection & Amount of time spent before security checks & Categorical \\
\hline & Transport from/to airport & Means of transport used to reach the airpont & Categorical \\
\hline
\end{tabular}

